\title{
Critically Evaluate the Understanding of Gender as Discourse
}

\author{
Changxue Xue \\ College of Foreign languages, Yanshan University \\ Qinhuangdao 066004, China \\ Tel: 86-335-805-8710_Email: changxue9@hotmail.com
}

\begin{abstract}
In this paper, the author explores the different views on gender and the nature of gender as discourse. Furthermore, the author argues that discursive psychology's views on gender are convincing and explain more than other perspectives of gender.
\end{abstract}

Keywords: Gender, Essentialism, Constructionism

Since the 1950s, an increasing use of the term gender has been seen in the academic literature and the public discourse for distinguishing gender identity from biological sex. Money and Hampson (1955) defined the term gender as what a person says or does to reveal that he or she has the status of being boy or girl, man or woman (masculinity or femininity of a person). Gender is a complex issue, constituents of which encompass styles of dressing, patterns of moving as well as ways of talking rather than just being limited to biological sex. Over the years, the perception of the issue 'gender' has been changing and developing from essentialism to social constructionism. Essentialism suggests that gender is a biological sex, by contrast, social constructionism suggests that gender is constructed within a social and cultural discourse. Due to its complex nature, gender intrigues numerous debates over the extent to which gender is a biological construct or a social construct.

Social constructionists employ discourse analysis as a method for research on gender identity. Discursive psychology is one of most important approaches within discourse analysis in the field of social psychology. In contrast to traditional cognitive psychology which treats language as a resource, providing clues as to what is going on inside people's minds or brains, discursive psychology sees language as its topics, examining the ways in which people talk about or construct things like attitudes, memories and emotions (Potter and Wetherell, 1987, cited in Edley, 2001). In this paper, the author explores the different views on gender and the nature of gender as discourse. Furthermore, the author argues that discursive psychology's views on gender are convincing and explain more than other perspectives of gender.

\section{Different Views on Gender}

There are different perspectives of gender with respect to its complexity. One of them is very typical of many people (ordinary people and some academicians). They believe that gender is tied to biology and is binary with categories of male and female. In this sense, gender is natural, stable and like something given by God, which means gender cannot be changed. That is to say, gender is biological sex, and it is an oversimplified and stereotypical vision of differentiating between genders. This view is problematic when it is used to interpret the real world around us because there are many cases that don't neatly fit into the two socially accepted categories. For example, in Indian culture, a hijra is considered a 'third gender' person, who is neither a woman nor a man. Most of them are male biologically or intersex, and they usually disclose themselves as women at the language level and dressing pattern. Hijras existed in India from the earliest records. And this 'third gender' was acknowledged in Indian culture throughout the Hindu history. Moreover, Lorber \& Farrell (1991, p.1) also note that "What stays constant is that women and men have to be distinguishable. Biology does not distinguish them-in the gender category "woman" you find male-to-female transsexuals, who have changed their genitals and hormonal output but not their chromosomes, and berdaches, who are biologically intact males living out their lives as social women."

Contrary to the biological view of gender, others, including sociologists, ethnographers and psychologists (Halford. \& Leonard. 2000) have argued that people are not born with behaviors and characteristics of being masculine or feminine, but gender identity is developed within a culture and society and is nurtured, and perpetuated by the culture. People are expected to comply with the norms within that culture, and are socialized and gendered in a way in which presupposed and ready-made behaviors and beliefs are constantly and repeatedly reinforced. Gender socialization is "like the making of a jelly or blancmange, the characters of new-born infants are initially quite fluid such that they can take on the shape or form of whatever 'mould' they are poured into. Socialization theories imply that it is only gradually that people begin 
to solidify into particular sorts of personalities. Once formed, we might 'wobble' a bit if pushed but, generally speaking, it is assumed that we will resist attempts to alter." (Edley, 2001, p.192) the Sociocultural view of gender is supported by the fact that hijras' (male-to-female transsexuals) social status is legitimatized because it is acknowledged throughout Vedic culture and by Islam rulers as well. They would undertake the cultural role of their chosen gender. However, there are still problems with this view. It denies that gender identity is dynamic and changing. A good example of this is that in many cultures, women are supposed to be nurturing, gentle, submissive and to be good homemakers. But in today's society, women hold important positions of power such as presidents and premiers or take on careers involving bravery and intelligence like pilots and scientists. This 'gender bending' doesn't create a new gender category. People have to fit into the two socially accepted categories (Lorber. \& Farrell, 1991). Thus, socialization theory ignores changes of gender role and cannot explain explicitly what is happening to the 'other' roles that women or men take on.

However, the first two theories cannot explain the following examples: There is a famous Chinese historical story about A girl called Hua Mulan. Hua Mulan's father was very old but was enrolled in the army. She had no brothers, but she was successfully passing as a man to fight in a war instead of her father. Sometimes, women politicians have to be thought as 'men', showing their masculinity to the public, to sit and work with other men politicians. Biological view sees gender as being fixed when people were born and by socialization theory, identity is once shaped in a social context and it is difficult to change. Hopefully, discursive psychology can explain such phenomena as the mentioned at the beginning of the paragraph. The discursive psychologists state that "gender is neither something into which we are born nor something that we eventually become. In terms of the same metaphor, we would argue that the jelly never sets. We claim that people's gender identities remain relatively fluid, capable of adapting to the particular social settings or contexts in which people find themselves."(Edley, 2001, p.192). Discursive psychology's view of gender as a powerful challenge to the essentialism and reductionism has developed biological and sociocultural theory of gender. In addition, discursive psychology gives better explanations to the complex gender. Discursive psychologists see gender as being fluid and dynamic and gender is constructed jointly and collectively through the interaction involving the operation of power because some ways of understanding the world become culturally dominant or hegemonic (Gramsci, 1971, cited in Edley, 2001). In addition, gender identity has to be negotiated and accomplished in the process of social interaction. What's more, there is no singular or unitary construction of a self, a multiplicity of different, even contradictory gender identities is produced. (Edley, 2001). We can see that gender identity is not fixed and not unalterable, but is realized through interaction within social, cultural context. Thus, in my view, discursive psychology's perspective on gender identity is more preferable than biological and sociocultural views on gender. More details about gender as discourse and discursive psychology and its correlation to gender are illustrated in the following parts.

\section{Gender as discourse}

Discursive psychologists insist that gender is constructed in and through discourse.

Gender is "the activity of managing situated conduct in light of normative conceptions of attitudes and activities appropriate for one's sex category. Gender activities emerge from and bolster claims to membership in a sex category" (Lorber \& Farrell, 1991, p.7). Discourse in terms of gender refers to "a whole range of different symbolic activities, including style of dress, patterns of consumption, ways of moving, as well as talking" (Edley, 2001, p.191). Gender identity is constructed and reproduced through these symbolic activities in a very broad sense. For example, within modern Chinese culture, masculinity is considered as something like being tough, drinking alcohol, smoking, having good sense of direction, having power and money. All these things are accepted and naturalized characteristics of male within the culture. In Goffman's (1976) terminology, 'gender display' focuses on behavioral aspects of being men or woman. Gender is expressed or exhibited through interaction and become normalized and recognized as a social organized achievement. Butler (1990) uses the concept of performativity to reveal gender as norms that require continual maintenance. Butler (1990) argues that performativity is the discursive mode (like vehicle) by which ontological effects are installed. Discourse is productive and performativity is considered as that aspect of discourse that has the capacity to produce what it specifies. According to Butler's (1990) theory of performativity, gender is not inscribed onto a biological body. On the contrary, gender is discursively constructed and sustained. Gender is performed by individuals on a daily basis and the everyday performance constructs gender within social and cultural discourse. In other words, she insists that gender identity is constructed within regulative discourses. Though Goffman and Butler adopt different terms of 'gender display' and 'performativity' respectively from gender as discourse by discursive psychologists, they actually provide support for discursive psychologists who maintain that gender is constructed in and through discourse with symbolic interaction within social and cultural norms.

According to discursive psychology, gender identity is not permanent, but in the course of being remade and reconstructed. However, reconstructing identities is not a simple matter of voluntary action (Eagleton, 1991, cited in Edley, 2001). Transforming the gender identity is a matter of challenging discourse. Reconsidering Garfinkel's (1967) case study of Agnes discloses a complex process of chosen gender identity reconstruction. Agnes, a transsexual, was brought up as boy and took female identity at the age of 17 and several years later, she had a sex reassignment operation. 
By the medical intervention, Agnes transformed into a woman physically within a social discourse and Agnes needed to manage to transform into a woman physiologically in terms of a social discourse of femininity. Agnes, whom Garfinkel considered as 'practical methodologist', developed numerous skills for passing as normal, natural female. She had to analyze and figure out how to act within cultural and social norms. She needed to perform herself as a woman and she had to learn to do what most women do without thinking. She had to face practical tasks such as managing the fact that she had male genitalia and she had no girl's biography which might be social sources in daily interaction. She employed the strategy of 'secret apprenticeship', through which she learned feminine manners by taking notice of her boyfriend's criticism of other women. According to Garfinkel (1967, p137), passing refers to the work of achieving and making secure their rights to live in the elected sex status while providing for the possibility of detection and ruin carried out within the socially structured conditions. In spite of Agnes' explicit management of performance of femininity, we cannot say Agnes had passed from a male to female completely though she had the operation and successful performance for years. She was still passing and facing an ongoing task of being a woman. Agnes's example shows that discursive reconstruction of new identity is complex and enduring process and it is restricted to social and cultural norms. To be successful, marking or displaying gender must be finely fitted to situations and modified or transformed as the occasion demands. Gender is something does, and does recurrently, in interaction with others (West and Zimmerman, 1991). Gender is embedded in cultural history and practices easily become routinized (habits). In addition, transformation and accomplishment of gender identity involves negotiation.

\section{Discursive Psychology and Discursive Psychology's View on Gender Identity}

Since discursive psychology provides us with richer thoughts for looking at the gender identity, we need to explain and illustrate explicitly what it is and how it works to help understand discursive construction of gender. Discursive psychology highlights the way people construct the world in everyday practice. The major assumption of discursive psychology is that the phenomena are constituted in and through discourse (Edwards \& Potter, 1992). Discursive psychology takes language as social practice and a way of doing things. Edwards and Potter (1992) also states that the world runs on talk and on writing. There are three basic constituents of discursive psychology and they are action, construction, and rhetoric. Discursive psychologists argue that in speaking and writing, people are performing actions and a detailed study of the discourse can disclose the essence of these actions. Their research has been based on naturalistic materials such as recordings of conversations in everyday and institutional settings, and documents such as newspaper articles and television programs. (Edwards \& Potter, 1992). Like social representation theory, discursive psychology is a social constructionist approach, but it is again different type of constructionism. Social representations theory is concerned with the way people make sense of the world through representations, whereas discursive psychology is concerned with how people construct versions of the world in the course of their everyday interactions, and the way these versions are established as real and independent of the speaker (Edwards \& Potter, 1992). Discursive psychologists have also argued that an analysis of rhetoric emphasizes the point that people interpret actions, their own mental life and the world and these interpretations are part of ongoing arguments, debates and dialogues (Billig, 1992).

Discursive psychology, based on the social constructionism, refutes the idea that the individual self consists of single, stable identity, and takes the self as being made up of multiple, discursively constructed identities, instead. For example, traditionally, Chinese men are in dominant, controlling position in family life. Accordingly, they are not supposed to do any housework which signifies the characteristics of femininity. Yet, society is changing and women work and earn as much as or even more than men. Nowadays, to see men cook at home. is not unusual Chinese men are enjoying acknowledgement of excellent cooking expertise. They are not called henpecked husband. The connotation of masculinity is changing as men interact with social conditions through the constant negotiation within the culture and this transformation is accepted and become part of the culture.

In Edley's (2001) view, there are three key concepts, namely, interpretative repertoires, ideological dilemmas and subject positions, in discursive psychology for describing and understanding construction of gender identity. Potter and Wetherell (1987, p.138, cited in Edley, 2001) defined interpretative repertoires as "basically a lexicon or register of terms and metaphors drawn upon to characterize and evaluate actions and events". Interpretative repertoires, in other words, are linguistic resources that can be drawn on, shared and understood in everyday social interaction and practices. Here is an example that was given by West and Zimmerman (1983, cited in Tannen, 1991) to show a man interrupting a woman. According to Tannen (1991), one of the most widely cited findings from research on gender and language is that men interrupt women.

Female: So uh you really can't bitch when you've got all those on the same day but I uh asked my physics professor if I couldn't change that.

Male: Don't touch that.

Female: What?

Male: I've got everything jus'how I want it in that notebook, you'll screw it up leafin' through it like that. 
This is an interruption because the man began while the woman was in the midde of a word 'change'. Here, the man's interruption is an interpretative repertoire, showing cultural history of masculinity. The interruption is justified in terms of interactional rights. There is the assumption that an interruption is a hostile and bullying act. The interrupter is seen as aggressor, the interrupted an innocent victim. These assumptions are founded on the premise that interruption is an intrusion, an attempt to dominate and control. In this case, it signifies masculinity of men in social practice. There are different interpretative repertoires, some are more available than others and this case reveal that man's position (masculinity) is dominant or hegemonic.

Ideological dilemmas means there is no unitary meaning to common sense. Common sense are full of contradictory /dilemmatic ideas. It implies that the different ways of talking about an object or event develop as opposing positions in an unfolding, historical, argumentative exchange (Edley, 2001). As for gender identity, it is widely accepted gender fall into two categories (male and female) in many cultures. However, there are still some cultures present different gender roles, so we are in dilemma when use polarized conception to interpret more complex phenomena. For example, Native Americans, if they have preferences to other sex, they are allowed to transform to the other sex and take on the role of their chosen gender. Their gender identity is quite complex and competing to fit into the binary gender identity in term of biological theory, but the transsexual does exist in the course of people's interaction with the world. Discursive psychology provides a constructionist framework for such phenomenon.

Subject position refers to "the way that ideology creates or constructs 'subjects' by drawing people into particular positions or identities" (Althusser, 1971, cited in Edley, 2001, p.209). Gender identity construction is a process of constructing intelligible subject positions. In terms of gender identity, it may refer to a person's preference and performance of gender roles through the interaction and this person becomes gendered in the process of subjectification which means "people are being both produced by and subjected to ideology"(Edley, 2001, p.209) For example, Nakhi, an ethnic group inhabit in Yunnan province in China. Nakhi Women are the main work-force in family. They do labour such as ploughing and reaping fields while Nakhi men stay at home cooking, looking after children. Women are highly respected in the Nakhi society. Behaviors and characteristics of Masculinity and femininity in Nakhi are quite different from other societies. Nakhi women's as subject are positioned in term of gender as being dominant, superior to Nakhi men. In this case, identity is formed by meeting the discourse of a culture. Construction of particular selves subjects to the ideology.

\section{Conclusion}

To conclude, biological and socialcultural perspectives of gender have their limitations and can't explain some phenomena which does exist within a culture. In contrast, discursive psychology has developed the theory of gender identity by drawing upon the social constructionism. Discursive psychology highlights the way people construct the world, the selves through interaction. Discursive psychologists claim that gender is constructed in and through discourse. Discursive psychologists see gender identity as something that is fluid, multiple, fragmentated, discursively constructed through interaction within the structures of a culture. In a word, discursive psychology's views on gender are convincing and explain more than other perspectives of gender.

\section{References}

Billig, M. (1992). Talking of the Royal Family. London: Routledge.

Butler, J. (1990). Gender Trouble: Feminism and the Subversion of Identity. London: Routledge.

Edley, N. (2001). Discourse as Data A Guide for Analysis. London: Sage: Publications Ltd. P.191 P.192

Edwards, D. Potter J. \& Middleton, D. (1992). Towards a Discursive Psychology of Remembering. The psychologist, p441-446.

Goffman, E. (1976). Gender advertisements. New York: Harper \& Row.

Garfinkel, H. (1967). Studies in Ethnomethodology. New Jersy: Prentice-Hall, Inc. p.137.

Halford. S \& Leonard. P. (2000). Gender, Power and Organisations. London: Palgrave Macmillan.

Lorber, J. \& Farrell, S. A. (1991). The Social Construction of Gender. California: SAGE Publications, Inc. p.1.

Money, J. \& Hampson, J. (1955). Hermaphroditism: recommendations concerning assignment of sex, change of sex, and psychologic management. Bulletin of the Johns. Hopkins Hospital 97: 284 - 300.

West, C. \& Zimmerman. (1991). The Social Construction of Gender. California: SAGE Publications, Inc.

Tannen, D. (1991). You Just Don't Understand: Women and Man in Conversation. London: Virago. 